\title{
Role of Grayscale and Color Doppler Ultrasonography in Evaluation of Scrotal Pathologies
}

\author{
Tushar Prabha ${ }^{1}$, Rohit Singh ${ }^{2}$, Sankalp Arora ${ }^{3}$
}

\begin{abstract}
Aim and objective: To study the spectrum of sonographic findings of various scrotal swellings and to assess the efficacy of grayscale and color Doppler sonography in the diagnosis of scrotal lesions.

Materials and methods: The group under study was comprised of 100 patients of all age groups with acute scrotal pain, painless, or painful scrotal swelling. All patients were scanned with the linear probe on the ultrasound machines GE Voluson S6, Toshiba Xario 100/Toshiba Acuson X 300 from January 2015 to November 2016.

Results: There were 128 various sonographic findings in total, at the final diagnosis, as some of the patients had more than one findings. Hydrocele was the most frequent fluid collection, one with the fluid being confined to the tunica vaginalis cavity (92.3\%). Varicocele comprised $11 \%$ of the total number of cases. At the final diagnosis, there were 11 cases of orchitis (57.1\%), some of the patients had more than one of the above three pathologies in different combinations. An incidence of inguinoscrotal hernia was noted in $8 \%$.

Conclusion: High-resolution sonography with color Doppler imaging could reliably define the morphological features and vascularity of scrotal lesions. Sonography was highly accurate in evaluating the consistency of scrotal mass-solid or cystic. Color Doppler was found extremely sensitive in the diagnosis and differentiation of testicular torsion and inflammation especially in the case of equivocal grayscale findings. Varicoceles were accurately diagnosed using color Doppler flow imaging (CDFI). The present study concludes that high-resolution sonography should be used as a first-line investigation. CDFI adds useful information and complement grayscale sonography in reaching a quick and correct diagnosis. Keywords: Epididymitis, Funiculitis, Gray scale, Orchitis, Scrotal.

Journal of Mahatma Gandhi University of Medical Sciences \& Technology (2020): 10.5005/jp-journals-10057-0123
\end{abstract}

\section{INTRODUCTION}

Scrotal swelling and pain are frequently encountered in clinical practice. Although in some patients history and physical examination are adequate to reach a diagnosis, yet in a large percentage of patients additional studies are required for a complete evaluation of their symptoms. The clinical examination is often misleading or nonspecific. Sometimes the presence of pain and/or swelling of scrotal contents precludes proper examination. Patients who present with acute onset of scrotal pain pose a diagnostic dilemma for the clinician. Traditionally, early exploration has been advocated. However, this may result in numerous needless operations, since it has been estimated that almost $80 \%$ of scrotal pathologies are inflammatory in nature.

In 1974, Miskin and Bain ${ }^{1}$ first reported the use of B mode ultrasonography to examine testes and scrotum. Dramatic advances within the last two decades in sonographic technology and instrumentation have been responsible for the emergence of ultrasonography as an indispensable diagnostic tool for the evaluation of scrotal pathology. The indications for the examination are many, e.g., palpable mass (hydrocele, epididymal cysts, tumor, inguinal hernia, varicocele, etc.), pain (infection, torsion, trauma), infertility (hypogonadism, varicocele), cryptorchidism (undescended testis) follow-up of the previous disease, and search for a possible primary tumor in a young man with retroperitoneal masses or in a man with a previous history of undescended testis.

Scrotal lesions can also be classified as testicular and extratesticular. The common testicular lesions are torsion, trauma, neoplasms, and inflammatory conditions. Extratesticular lesions include lesions of the spermatic cord, the epididymis, and the

\begin{abstract}
1,2Department of Radiodiagnosis, Mahatma Gandhi Medical College and Hospital, Mahatma Gandhi University of Medical Sciences and Technology, Jaipur, Rajasthan, India

${ }^{3}$ All India Institute of Medical Sciences, Jodhpur, Rajasthan, India

Corresponding Author:Tushar Prabha, Department of Radiodiagnosis, Mahatma Gandhi Medical College and Hospital, Mahatma Gandhi University of Medical Sciences and Technology, Jaipur, Rajasthan, India, e-mail: drtusharpr345@gmail.com
\end{abstract}

How to cite this article: Prabha T, Singh R, Arora S. Role of Grayscale and Color Doppler Ultrasonography in Evaluation of Scrotal Pathologies. J Mahatma Gandhi Univ Med Sci Tech 2020;5(1):16-22.

Source of support: Nil

Conflict of interest: None

scrotal wall. This distinction is important because extratesticular masses are almost always benign while intratesticular solid masses may be malignant.

High-resolution real-time ultrasonography has demonstrated a high degree of accuracy and sensitivity in the detection, characterization, and localization of intrascrotal abnormalities. High-resolution color Doppler ultrasound has made it possible to noninvasively image and evaluate small vessels in superficial organs. To date, the superficial organ in which the color Doppler flow index has the greatest impact is the testes. It has narrowed the number of clinical diagnostic possibilities considered in the differential diagnosis and thus limited the need for the surgical exploration of the scrotum and helped to make a specific diagnosis in cases of acute scrotal pain.

(c) The Author(s). 2020 Open Access This article is distributed under the terms of the Creative Commons Attribution 4.0 International License (https:// creativecommons.org/licenses/by-nc/4.0/), which permits unrestricted use, distribution, and non-commercial reproduction in any medium, provided you give appropriate credit to the original author(s) and the source, provide a link to the Creative Commons license, and indicate if changes were made. The Creative Commons Public Domain Dedication waiver (http://creativecommons.org/publicdomain/zero/1.0/) applies to the data made available in this article, unless otherwise stated. 


\section{Materials and Methods}

The present study was done in the Department of Radiodiagnosis of Mahatma Gandhi Medical College and Hospital, Jaipur on USG Machines GE Voluson S6/Toshiba Xario 100/Toshiba Acuson X 300 from January 2015 to November 2016. The group under study was comprised of 100 patients of all age groups attending the various outdoor and indoor departments of the hospital with signs and symptoms related to scrotal diseases. For example, the patient presenting with acute scrotal pain and the patient presenting with painless or painful scrotal swelling (Figs 1 to 4).

Relevant history was taken about clinical symptoms and the presenting complaints. Bimanual palpation was performed in all cases to determine the status of scrotal contents. Real-time grayscale ultrasound and color Doppler study was done on USG Machines (frequency 7-12 MHz linear array transducer as and when required 3.5-transducer was also used for adequate penetration, particularly in case of large scrotal swelling and retroperitoneal lymphadenopathy). The scrotum was elevated and supported and scanned in the supine position from anterior, lateral, and inferior surfaces in the longitudinal and transverse plane. The examination was further continued to evaluate the spermatic cord and groin region when required. In cases of varicocele, the examination was performed in the supine posture, erect posture, and Valsalva maneuver to confirm it.

Comparison of the symptomatic side was done with the asymptomatic side and findings were analyzed. In patients with suspicion of testicular tumors, the kidney, liver, and para-aortic regions were scanned to look for the presence of secondaries and any backpressure changes in the kidneys.

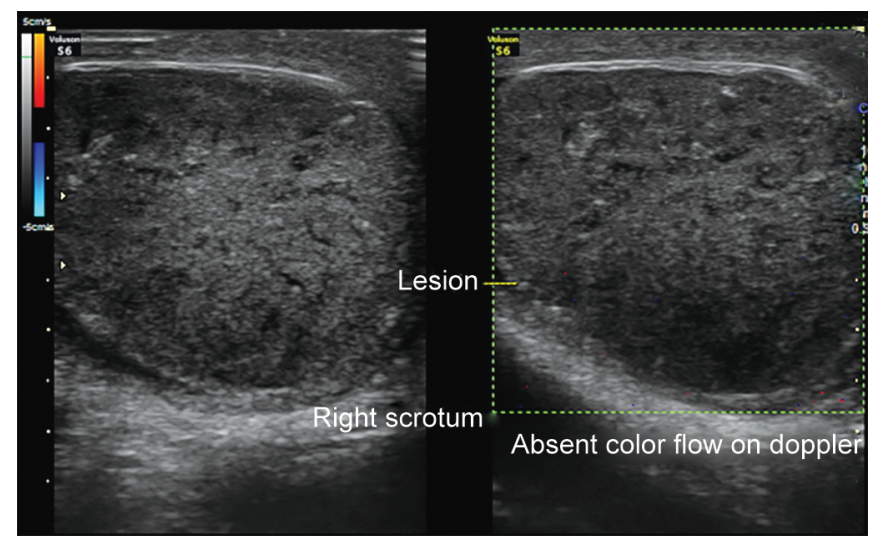

Fig. 1: Heterogeneous echotexture of right testes with the absence of color flow on color Doppler-torsion testes

\section{Observations and Results}

A total of 100 patients with clinical symptoms pertaining to the scrotal pathology, referred from the outpatient department, were assessed by high-resolution ultrasound. Observations are shown in Tables 1 to 8.

Fluid collections were the commonest abnormality detected on sonography. Hydrocele was seen in 34 (34\%) cases and was the most frequent fluid collection. The most common type of hydrocele was the one with the fluid being confined to the tunica vaginalis cavity (92.3\%). Focal anechoic collection superior to the testis and epididymis, suggestive of encysted hydrocele of the spermatic cord was noted in 2 cases (7.7\%). Septations and internal echoes are more common in hematocele than hydrocele (Table 3).

Varicocele comprised $11 \%$ of the total number of cases and $8.3 \%$ of total pathological lesions. The maximum vessel diameter was $>4$ $\mathrm{mm}$ in 4 cases $(37.5 \%)$ in erect posture while tortuosity of vessels was noted in 8 cases (66\%). All cases demonstrated accentuation on the Valsalva maneuver and on assuming erect posture (Table 4).

At the final diagnosis, there were 11 cases of orchitis (57.1\%), 14 cases of epididymitis (78.6\%), and 3 cases (14.3\%) of funiculitis in these 18 patients, as some of the patients had more than one of the above three pathologies in different combinations (Table 5).

At the final diagnosis, testes were involved in four cases $(50 \%)$ and epididymis in seven cases (83.33\%). In the majority of these cases (three out of five cases), the involved epididymis was heterogeneous in echotexture (66\%) followed by hypoechoic echotexture in one case (18\%) and normal echotexture in one case (18\%). Calcifications are seen in chronic inflammation of testis and epididymis three cases for each of them (Table 6).

Omentum was seen herniating into the inguinoscrotal region in three cases while bowel loops in five cases. Thus, an incidence of inguinoscrotal hernia was noted at $8 \%$ (Table 8 ). The color flow study was $100 \%$ accurate in the diagnosis of torsion (Table 7 ).

\section{Discussion}

Epididymitis and epididymo-orchitis are the most common causes of acute scrotal pain. In epididymitis, nearly $20 \%$ of the patients there is the involvement of the testis. ${ }^{2}$ Brown et al. ${ }^{3}$ established the quantitative Doppler criteria for acute unilateral epididymitis and orchitis. A peak systolic velocity (PSV) $\geq 15 \mathrm{~cm} / \mathrm{second}$ produced diagnostic accuracy of $90 \%$ for orchitis and $93 \%$ for epididymitis. Mevorach and Lerner ${ }^{4}$ could demonstrate a good correlation between ultrasound and pathological findings in eight surgically proven cases of a testicular abscess. Garriga et al. ${ }^{5}$ evaluated the grayscale and power Doppler sonographic appearances in 20 cases of acute inflammatory diseases of the scrotum. They concluded that though power Doppler may not be superior to color Doppler
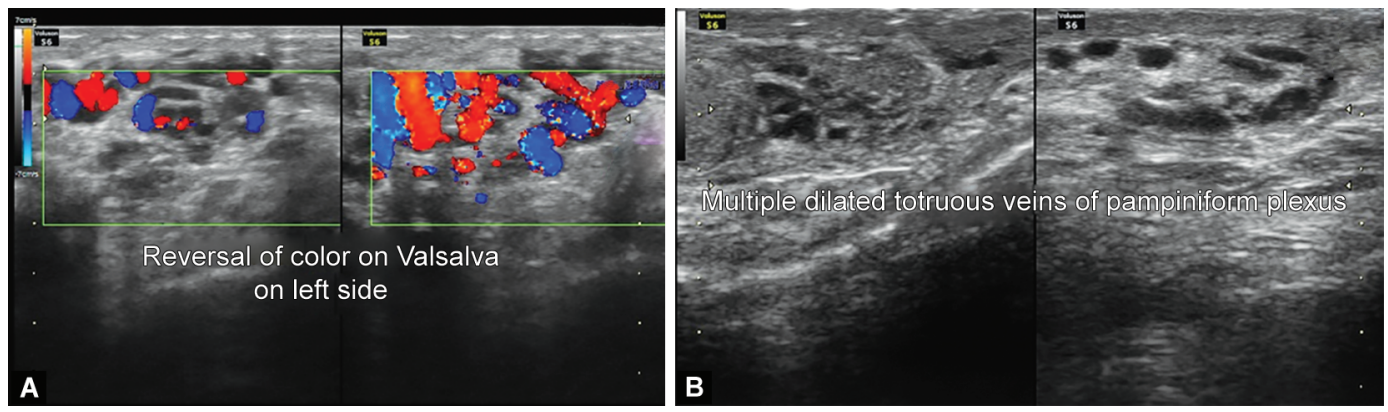

Figs 2A and B: Multiple dilated tortuous veins of pampiniform plexus with reversal of color flow on Valsalva-left-sided varicocele 

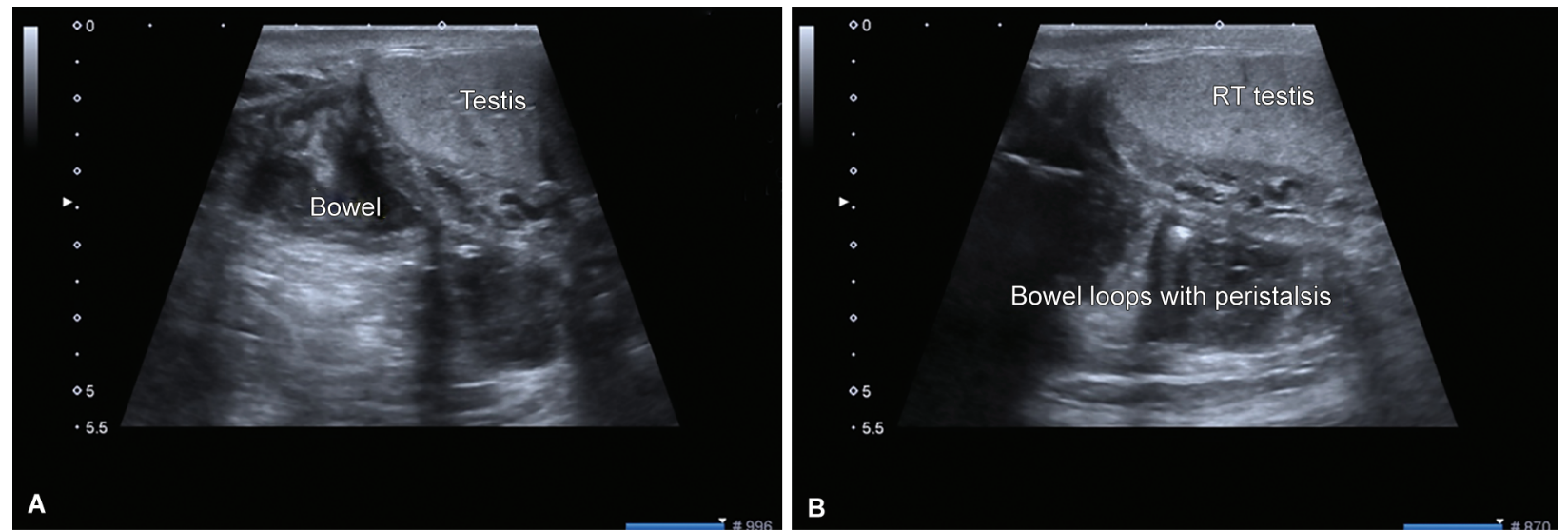

A

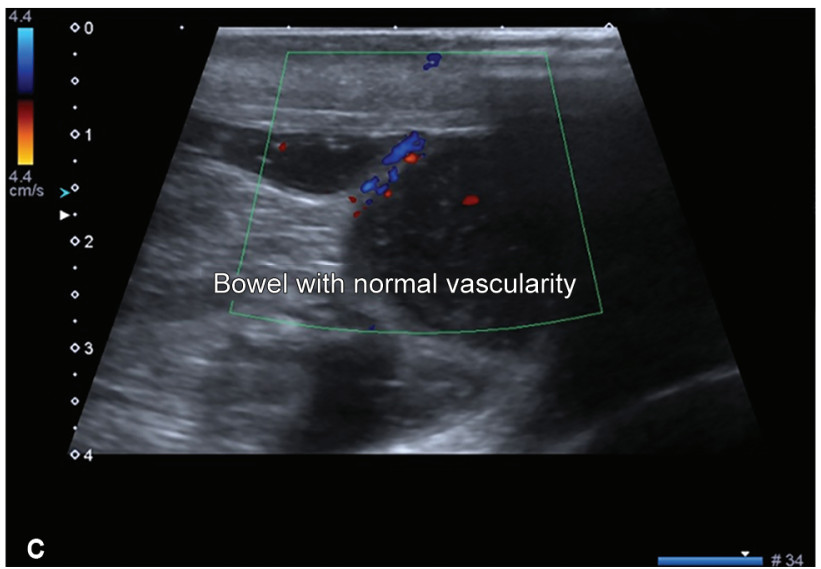

Figs $3 \mathrm{~A}$ to C: Bowel loops herniating in the right inguinal region with peristalsis and with vascularity: right inguinoscrotal hernia
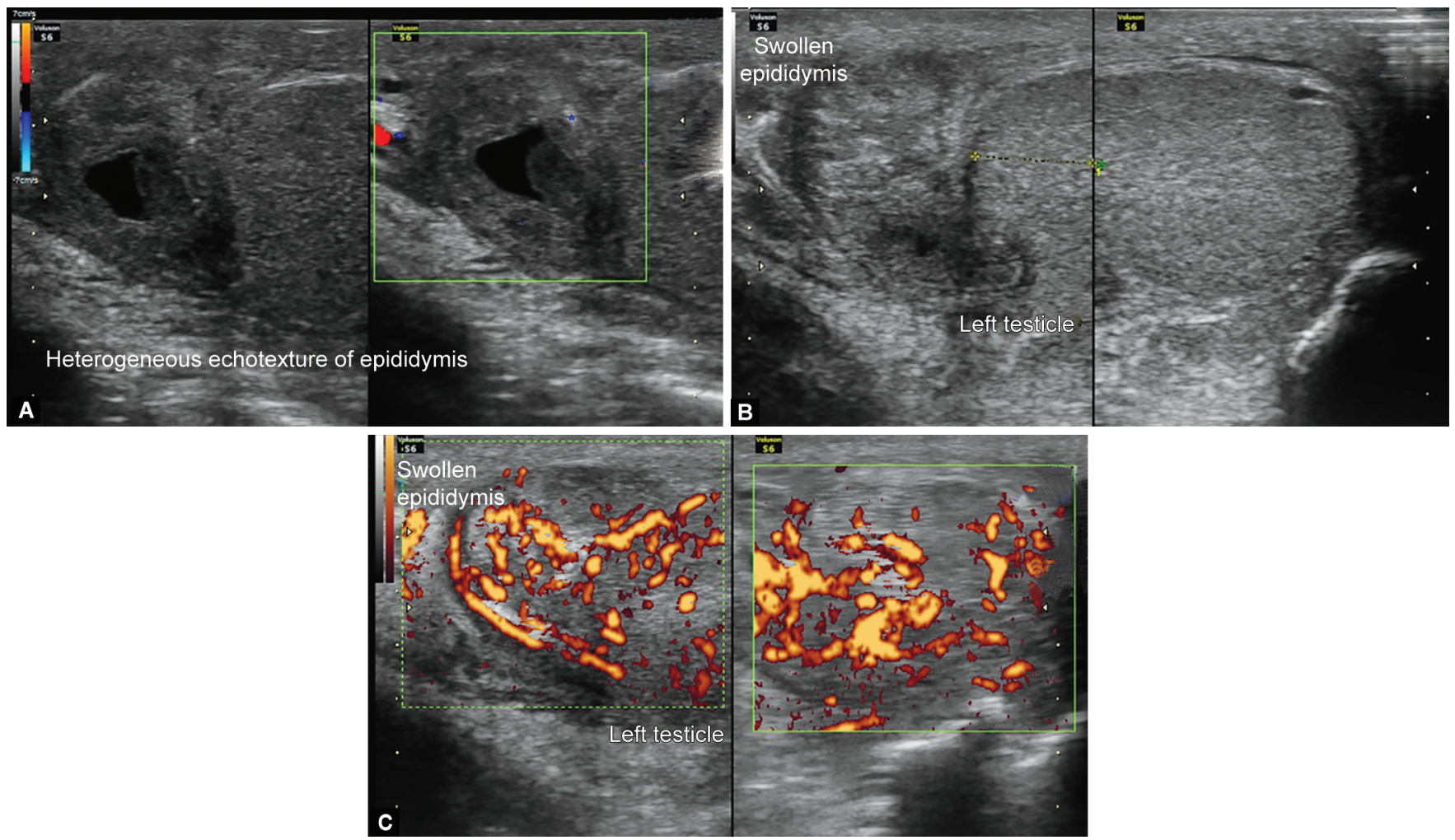

Figs 4A to C: (A) Thick-walled collection in the left epididymal head with heterogeneous echotexture; (B) Left epididymis appears swollen and thickened on the gray scale; (C) Left testis shows increased color flow-left epididymal abscess with epididymo-orchitis 
Table 1: Extratesticular lesions

\begin{tabular}{rlll}
\hline S.no. & Pathology & No. of cases & $\%$ \\
\hline 1 & Hydrocele & 34 & 33.7 \\
2 & Acute epididymitis & 14 & 14.3 \\
3 & Varicocele & 11 & 10.3 \\
4 & Chronic epididymitis & 7 & 6.5 \\
5 & Epididymal cyst & 7 & 6.5 \\
6 & Spermatocele & 4 & 3.9 \\
7 & Hernia & 8 & 7.8 \\
8 & Hematocele & 3 & 2.6 \\
9 & Extratesticular abscess & 2 & 2.6 \\
10 & Funiculitis & 2 & 2.6 \\
11 & Scrotolith & 1 & 1.3 \\
12 & Pyocele & 7 & 6.5 \\
13 & Fournier's gangrene & 1 & 1.3 \\
\hline
\end{tabular}

Table 2: Intratesticular lesions $(n=36)$

\begin{tabular}{cllc}
\hline S. no. & Pathology & No. of cases & $\%$ \\
\hline 1 & Acute orchitis & 9 & 28.5 \\
2 & Torsion & 3 & 7.14 \\
3 & Testicular tumor & 3 & 3.57 \\
4 & Chronic orchitis & 3 & 10.7 \\
5 & Testicular atrophy & 3 & 7.14 \\
6 & Undescended testis & 4 & 10.7 \\
7 & Testicular cyst & 3 & 7.14 \\
8 & Ectasia of rete testis & 5 & 14.2 \\
9 & Testicular microlithiasis & 1 & 3.57 \\
10 & Testicular trauma & 1 & 3.57 \\
11 & Testicular abscess & 1 & 3.57 \\
\hline
\end{tabular}

Table 3: Sonographic features of fluid collections in tunica vaginalis sac $(n=37)$

\begin{tabular}{|c|c|c|c|c|c|}
\hline S. no. & Ultrasound features & Hydrocele $(n=34)$ & $\%$ & Hematocele $(n=3)$ & $\%$ \\
\hline \multirow[t]{3}{*}{1} & Site & & & & \\
\hline & Tunica vaginalis cavity & 32 & 92.3 & 3 & 100 \\
\hline & Encysted in spermatic cord & 2 & 7.7 & 0 & 0 \\
\hline \multirow[t]{4}{*}{2} & Size & & & & \\
\hline & Minimal & 16 & 46.1 & 2 & 66 \\
\hline & Moderate & 10 & 30.7 & 1 & 34 \\
\hline & Large & 8 & 23 & 0 & 0 \\
\hline \multirow[t]{3}{*}{3} & Internal echoes & & & & \\
\hline & Present & 13 & 38.5 & 3 & 100 \\
\hline & Absent & 21 & 61.5 & 0 & 0 \\
\hline \multirow[t]{3}{*}{4} & Septations & & & & \\
\hline & Absent & 24 & 69.2 & 3 & 100 \\
\hline & Present & 10 & 30.8 & 0 & 0 \\
\hline \multirow[t]{4}{*}{5} & Associated finding & & & & \\
\hline & Inflammatory disease & 16 & 46.1 & 0 & 0 \\
\hline & Hernia & 5 & 15.3 & 0 & 0 \\
\hline & Torsion & 1 & 3.8 & 0 & 0 \\
\hline
\end{tabular}

Table 4: Sonographic features of varicocele $(n=11)$

\begin{tabular}{|c|c|c|c|}
\hline S. no. & Ultrasound features & $\begin{array}{l}\text { No. of cases } \\
(n=11)\end{array}$ & $\%$ \\
\hline \multirow[t]{4}{*}{1} & \multicolumn{3}{|c|}{ Maximum diameter of spermatic/intratesticular veins } \\
\hline & $2-3 \mathrm{~mm}$ & 3 & 25 \\
\hline & $3-4 \mathrm{~mm}$ & 4 & 37.5 \\
\hline & $>4 \mathrm{~mm}$ & 4 & 37.5 \\
\hline \multirow[t]{3}{*}{2} & Tortuosity & & \\
\hline & Present & 8 & 66 \\
\hline & Absent & 3 & 34 \\
\hline \multirow[t]{3}{*}{3} & Accentuation on & & \\
\hline & Valsalva & 11 & 100 \\
\hline & Erect posture & 9 & 87.5 \\
\hline \multirow[t]{5}{*}{4} & Color Doppler (CD) & & \\
\hline & Grade 0: no flow & 0 & 0 \\
\hline & Grade I spotty flow & 0 & 0 \\
\hline & Grade II scattered flow & 3 & 34 \\
\hline & Grade III continuous flow & 8 & 66 \\
\hline
\end{tabular}

in diagnosing inflammatory diseases, it is easier and faster to use than color Doppler in evaluating these diseases.

Chronic inflammation and tuberculous epididymitis occur by retrograde extension from the prostate and seminal vesicles and also from hematogenous dissemination or perivasal lymphatics. ${ }^{6}$ Gow ${ }^{7}$ showed that disease predominantly involves epididymis of one side. They reported associated orchitis in $14 \%$ of their patients.

Kim et al. ${ }^{8}$ performed scrotal sonography in 10 patients with tuberculous epididymitis. They found enlarged epididymis with marked heterogeneity, associated testis involved was also present. The testis, epididymis, and tunica vaginalis had areas of calcification occasionally.

Although Kim et al. ${ }^{8}$ showed that disease primarily starts in the tail of the epididymis, this sign was not seen in the series of Chung et al. ${ }^{9}$ Kim et al. ${ }^{8}$ suggested that an enlarged and heterogeneous epididymis is reliable in differentiating tuberculous from nontuberculous epididymitis.

Chung et al. ${ }^{9}$ evaluated 22 patients with tuberculous epididymis and/or orchitis and concluded that heterogeneous and hypoechoic 


\begin{tabular}{|c|c|c|c|c|c|c|c|}
\hline \multirow[b]{2}{*}{ S. no. } & \multirow[b]{2}{*}{ Ultrasound features } & \multicolumn{2}{|c|}{ Testis $(n=11)$} & \multicolumn{2}{|c|}{ Epididymis $(n=14)$} & \multicolumn{2}{|c|}{ Spermatic cord $(n=3)$} \\
\hline & & No. of cases & $\%$ & No. of cases & $\%$ & No. of cases & $\%$ \\
\hline \multirow[t]{3}{*}{1} & Side & & & & & & \\
\hline & Unilateral & 7 & 62.5 & 9 & 63.7 & 2 & 66 \\
\hline & Bilateral & 4 & 37.5 & 5 & 36.3 & 1 & 34 \\
\hline \multirow[t]{4}{*}{2} & Size & & & & & & \\
\hline & Normal & 3 & 27 & 1 & 9.09 & 0 & 0 \\
\hline & Increased & 8 & 73 & 13 & 90.9 & 3 & 100 \\
\hline & Decreased & 0 & 0 & 0 & 0 & 0 & 0 \\
\hline \multirow[t]{5}{*}{3} & Echotexture & & & & & & \\
\hline & Normal & 3 & 27 & 0 & 0 & 0 & 0 \\
\hline & Hypoechoic & 8 & 73 & 5 & 36.3 & 0 & 0 \\
\hline & Hyperechoic & 0 & 0 & 6 & 45.4 & 0 & 0 \\
\hline & Heterogeneous & 0 & 0 & 3 & 18.2 & 3 & 100 \\
\hline \multirow[t]{3}{*}{4} & Involvement pattern & & & & & & \\
\hline & Focal & 0 & 0 & 8 & 54.5 & 0 & 0 \\
\hline & Diffuse & 11 & 100 & 6 & 45.4 & 3 & 100 \\
\hline \multirow[t]{5}{*}{5} & Associated findings & & & & & & \\
\hline & Involvement of epididymis & 7 & 62.5 & - & - & 3 & 100 \\
\hline & Involvement of testis & - & - & 6 & 45.4 & 3 & 100 \\
\hline & Involvement of spermatic cord & 3 & 25 & 3 & 18.2 & - & - \\
\hline & Peritesticular fluid & 10 & 87.5 & 11 & 81.8 & 3 & 100 \\
\hline
\end{tabular}

Table 6: Grayscale features of chronic inflammation $(n=8)$

\begin{tabular}{|c|c|c|c|c|c|}
\hline \multirow[b]{2}{*}{ S. no. } & \multirow[b]{2}{*}{ Grayscale features } & \multicolumn{2}{|c|}{ Testis $(n=4)$} & \multicolumn{2}{|c|}{ Epididymis $(n=7)$} \\
\hline & & No. of cases & $\%$ & No. of cases & $\%$ \\
\hline \multirow[t]{3}{*}{1} & Side & & & & \\
\hline & Unilateral & 3 & 75 & 6 & 85.7 \\
\hline & Bilateral & 1 & 25 & 1 & 14.3 \\
\hline \multirow[t]{4}{*}{2} & Size & & & & \\
\hline & Normal & 3 & 75 & 3 & 42.9 \\
\hline & Increased & 1 & 25 & 4 & 57.1 \\
\hline & Decreased & 0 & 0 & 0 & 0 \\
\hline \multirow[t]{5}{*}{3} & Echotexture & & & & \\
\hline & Normal & 0 & 0 & 1 & 18 \\
\hline & Hypoechoic & 3 & 75 & 1 & 18 \\
\hline & Hyperechoic & 0 & 0 & 0 & 0 \\
\hline & Heterogeneous & 1 & 25 & 5 & 64 \\
\hline \multirow[t]{3}{*}{4} & Calcification & & & & \\
\hline & Present & 3 & 75 & 3 & 40 \\
\hline & Absent & 1 & 25 & 4 & 60 \\
\hline \multirow[t]{3}{*}{5} & Peritesticular fluid & & & & \\
\hline & Present & 1 & 25 & 3 & 40 \\
\hline & Absent & 3 & 75 & 4 & 60 \\
\hline
\end{tabular}

swelling of the epididymis and/or testis, with associated sinus tract or extratesticular calcification, may be helpful in the diagnosis of the above condition. Tuberculous orchitis with no epididymal involvement was very rare.

Testicular torsion occurs when the spermatic cord is twisted and it has been argued that the correct term should be spermatic cord torsion. ${ }^{10}$ The predisposing condition is the presence of a short mesenteric attachment of the testis, the bell clapper deformity.
Sidhu ${ }^{11}$ reviewed the clinical features and role of color Doppler sonography. They suggested that color Doppler sonography can reliably image acute epididymo-orchitis but there is no imaging gold standard for spermatic cord torsion and that although useful for torsion, color Doppler sonography is not infallible. Arce et al. ${ }^{12}$ conducted a study to evaluate the importance of direct spermatic cord imaging in the sonographic diagnosis of acute spermatic cord torsion. Sonography showed a rotation of the spermatic cord on 
Table 7: Sonographic features of torsion testis $(n=3)$

\begin{tabular}{|c|c|c|c|}
\hline \multirow[b]{2}{*}{ S. no. } & \multirow[b]{2}{*}{ Ultrasound features } & \multicolumn{2}{|c|}{ Total cases $(n=3)$} \\
\hline & & No. of cases & $\%$ \\
\hline \multirow[t]{4}{*}{1} & Size & & \\
\hline & Normal & 0 & 0 \\
\hline & Increased & 3 & 100 \\
\hline & Decreased & 0 & 0 \\
\hline \multirow[t]{5}{*}{2} & Echotexture & & \\
\hline & Normal & 0 & 0 \\
\hline & Hypoechoic & 1 & 34 \\
\hline & Hyperechoic & 0 & 0 \\
\hline & Heterogeneous & 2 & 66 \\
\hline \multirow[t]{3}{*}{3} & Peritesticular fluid & & \\
\hline & Absent & 1 & 34 \\
\hline & Present & 2 & 66 \\
\hline \multirow[t]{5}{*}{4} & Color Doppler & & \\
\hline & Grade 0: no flow & 3 & 100 \\
\hline & Grade I: spotty flow & 0 & 0 \\
\hline & Grade II: multiple scattered flow & 0 & 0 \\
\hline & Grade III: continuous flow & 0 & 0 \\
\hline
\end{tabular}

Table 8: Sonographic features in the inguinoscrotal hernia $(n=8)$

\begin{tabular}{|c|c|c|c|c|c|}
\hline \multirow[b]{2}{*}{ S. no. } & \multirow[b]{2}{*}{ Sonography feature } & \multicolumn{2}{|c|}{ Omentocele $(n=3)$} & \multicolumn{2}{|c|}{ Enterocele $(n=5)$} \\
\hline & & No. of cases & $\%$ & No. of cases & $\%$ \\
\hline 1 & Number & 3 & 37.5 & 5 & 62.5 \\
\hline \multirow[t]{4}{*}{2} & Echopattern & & & & \\
\hline & Normal & 0 & 0 & 0 & 0 \\
\hline & Нуро & 0 & 0 & 5 & 100 \\
\hline & Hyper & 3 & 100 & 0 & 0 \\
\hline \multirow[t]{5}{*}{3} & CDFI (within mass) & & & & \\
\hline & Gr 0 & 0 & 0 & 3 & 60 \\
\hline & Gr 1 & 0 & 0 & 2 & 40 \\
\hline & Gr 2 & 3 & 100 & 0 & 0 \\
\hline & Gr 3 & 0 & 0 & 0 & 0 \\
\hline \multirow[t]{2}{*}{4} & Associated findings & & & & \\
\hline & Hydrocele & 0 & 0 & 5 & 100 \\
\hline
\end{tabular}

the symptomatic side in all the patients. They thus concluded that finding of the rotated spermatic cord could be a highly reliable and direct sign for the diagnosis of a testicular torsion and is especially important when the intratesticular flow is present on color Doppler on the symptomatic side. Patriquin and Yazbeck ${ }^{13}$ used color Doppler sonography to study 65 boys aged $0-18$ years. They concluded that color Doppler sonography for torsion in boys aged $0-18$ years has a sensitivity of $89 \%$ and a specificity of $100 \%$.

Subramanyam et al. ${ }^{14}$ performed sonography on six patients with a scrotal hernia which revealed an anechoic mass surrounding the normal testicular elements in cases of small bowel hernia or a highly echogenic mass separated from the testis in omental hernia, correlating with the present study. Dogra et al. ${ }^{15}$ suggested that the presence of real-time peristalsis is diagnostic of bowel in case of scrotal hernia.
Ultrasound is of great value in examination of the testis rendered impalpable by large surrounding hydrocele. ${ }^{16} \mathrm{It}$ is seen as an anechoic collection with good sound transmission. Occasionally, there can be internal echoes or hyperechoic fluid which is related to the presence of cholesterol crystals in the hydrocele fluid. ${ }^{16}$

Dogra et al. ${ }^{15}$ reviewed the sonographic features of hematocele and pyocele and reported that at sonography both conditions look like complex cystic lesions with internal septations and loculations. Our study also showed the same.

Varicocele has been reported to be present in approximately $10 \%$ of adolescents past the age of puberty and in $15 \%$ of an adult man. ${ }^{17}$ The ultrasound appearance of varicocele consists of multiple, hypoechoic, serpiginous, tubular structures larger than $2 \mathrm{~mm}$ in diameter that is best visible superior and/or lateral to the testis. ${ }^{15}$ 
Dhabuwala et al. ${ }^{18}$ studied 178 subfertile men by continuous Doppler technique and classified reflux into three grades for the detection of varicocele. Hirsch et al. ${ }^{19}$ judged continuous Doppler too sensitive to detect reflux as $40 \%$ of cases of reflux detected by Doppler had negative selective venography. Chiou et al. ${ }^{20}$ developed a new scoring system incorporating the maximal venous diameter (score $0-3$ ), the presence of a venous plexus and the sum of the diameters of veins in the plexus (score $0-3$ ), and change of flow on Valsalva (0-3). Using a score of 4 or more to define the presence of CDFI positive varicocele, they observed the sensitivity of $95 \%$ and specificity of $85 \%$ when compared to clinical examination. Liguori et al. ${ }^{21}$ reviewed the color Doppler ultrasound as an investigation for diagnosing varicocele which allows the detection of even subclinical varicocele by measuring the venous diameter and flow parameters.

\section{ConcLusion}

The various parameters in scrotal diseases have been studied and evaluated sonographically (on basis of grayscale and color Doppler flow index) in the background of clinical history. Based on this study we concluded that:

- High-resolution sonography with color Doppler imaging could reliably define the morphological features and vascularity of scrotal lesions.

- Sonography was highly accurate in evaluating the consistency of scrotal mass-solid or cystic. An accuracy of $100 \%$ in this regard, was achieved in the study.

- Sonography was found to be $100 \%$ sensitive in the diagnosis of hydrocele. Furthermore, it helped in evaluating the integrity and size of testes in the case associated with large hydroceles, which is difficult clinically. Sonography could distinguish idiopathic hydrocele from that following trauma, infections, and lymphatic obstruction.

- Inflammatory scrotal pathologies were diagnosed easily by high-resolution sonography with high accuracy. The extent of testicular and epididymal involvement was reliably detected with the presence of any associated fluid collection.

- In cases of scrotal hernias, the hernial contents were well evaluated by sonography. Bowel and fat content were diagnosed and distinguished from each other.

- Color Doppler was found extremely sensitive in the diagnosis and differentiation of testicular torsion and inflammation especially in the case of equivocal grayscale findings.

- Varicoceles were accurately diagnosed using CDFI.

The present study concludes that high-resolution sonography along with color Doppler flow imaging (CDFI) should be used as the first-line investigation in the evaluation of scrotal pathologies. CDFI add useful information and complement grayscale sonography in reaching a quick and correct diagnosis.

\section{References}

1. Miskin M, Bain J. Bmode ultrasonic examination of the testes. J Clin Ultrasound 1974;2(4):307-311. DOI: 10.1002/jcu.1870020412.
2. Horstman WB, Middleton WD, Melson GL. Scrotal inflammatory disease: color Doppler US findings. Radiology 1991;179(1):55-59. DOI: 10.1148/radiology.179.1.2006304.

3. Brown JM, Hammers LW, Barton JW. Quantitative Doppler assessment of acute scrotal inflammation. Radiology 1995;197(2):427-431. DOI: 10.1148/radiology.197.2.7480687.

4. Mevorach RA, Lerner RM. Testicular abscess: diagnosis by ultrasound. J Urol 1986;136(6):12-13. DOI: 10.1016/S0022-5347(17)45286-4.

5. Garriga VF, Xavier PC, Elena GA, et al. Grey scale and power Doppler sonographic appearances of acute inflammatory diseases of the scrotum. J Clin Ultrasound 2000;28(2):67-72. DOI: 10.1002/(SICI)10970096(200002)28:2<67::AID-JCU2>3.0.CO;2-6.

6. Koyama Y, Ligaya T, Saito S. Tuberculous epididymo-orchitis. Urology 1988;31(5):4-19. DOI: 10.1016/0090-4295(88)90739-X.

7. Gow JG. Genitourinary tuberculosis. In: Campbell's Urology Walsh PC, Gittes RF, Permutler AD, et al., ed., vol. 1, ch. 23 5th ed., Philadelphia: WB Saunders Co.; 1986. p. 1045.

8. Kim SH, Pollack HM, Cho KS, et al. Tuberculous epididymitis and epididymo-orchitis: sonographic findings. J Urol 1993;150(1):180-184. DOI: 10.1016/S0022-5347(17)35404-6.

9. Chung JJ, Kim MJ, Lee T, et al. Sonographic findings in tuberculous epididymitis and epididymo-orchitis. JClin Ultrasound 1997;25(7):390394. DOI: 10.1002/(SICI)1097-0096(199709)25:7<390::AIDJCU7>3.0.CO;2-5.

10. Allan WR, Brown RB. Torsion of the testes: a review of 58 cases. $\mathrm{Br}$ Med J 1996;1(5500):1396-1397. DOI: 10.1136/bmj.1.5500.1396.

11. Sidhu PS. Clinical and imaging features of testicular torsion: role of ultrasound. Clin Radiol 1999;54(6):343-352. DOI: 10.1053/ crad.1999.0178.

12. Arce JD, Cortes M, Vargas JC. Sonographic diagnosis of acute spermatic cord torsion. Rotation of the cord: a key to the diagnosis. Pediatr Radiol 2002;32(7):485-491. DOI: 10.1007/s00247-0020701-z.

13. Patriquin HB, Yazbeck S. Testicular torsion in infants and children. Diagnosis with colour Doppler sonography. Radiology 1993;188(3):758-781. DOI: 10.1148/radiology.188.3.8351347.

14. Subramanyam BR, Balthazar EJ, Raghvendra BN, et al. Sonographic diagnosis of scrotal hernia. Am J Roentgenol 1982;139(3):535-553. DOI: 10.2214/ajr.139.3.535.

15. Dogra VS, Gottlieb RH, Mayumi O, et al. Sonography of the scrotum. Radiology 2003;227(1):18-36. DOI: 10.1148/radiol.2271001744.

16. Leung ML, Gooding GAW, Williams RD. High-resolution sonography of scrotal contents in asymptomatic subjects. Am J Roentgenol 1984;143(1):161-164. DOI: 10.2214/ajr.143.1.161.

17. Meecham RB, Townsend RR, Rademacher $D$, et al. The incidence of varicoceles in the general population when evaluate by physical examination, grey scale sonography and color Doppler sonography. J Urol 1994;151(6):1535-1538. DOI: 10.1016/S0022-5347(17) 35295-3.

18. Dhabuwala C, Kumar A, Kerkar P, et al. Patern of Doppler recordings and its relationship to varicocele in infertile men. Int J Androl 1989;12(6):430-438. DOI: 10.1111/j.1365-2605.1989.tb01333.x.

19. Hirsch AV, Camerson KM, Tyler JP. The Doppler assessment of varicoceles and internal spermatic vein reflux in infertile men. $\mathrm{Br} J$ Urol 1980;52(1):50-55. DOI: 10.1111/j.1464-410X.1980.tb02919.x.

20. Chiou RK, Anderson JC, Wobig RK. Color Doppler ultrasound criteria to diagnose varicoceles: correlation of a new scoring system with physical examination. Urilogy 1997;50(6):953-956. DOI: 10.1016/ S0090-4295(97)00452-4.

21. Liguori G, Trombetta C, Garaffa G, et al. Color Doppler ultrasound investigation of varicocele. World J Urol 2004;22(5):378-381. DOI: 10.1007/s00345-004-0421-0. 